\title{
Oxytocin Antagonist
}

National Cancer Institute

\section{Source}

National Cancer Institute. Oxytocin Antagonist. NCI Thesaurus. Code C98292.

Any of the synthetic agents that inhibit or antagonize the biosynthesis or biologic effects

of oxytocin by either antagonizing the responsiveness of oxytocin sensitive tissues or competing with its binding sites. 